\title{
Evaluation and Optimization Production Of Low Permeability Carbonate Reservoir By Hydraulic Fracturing In "Jaso Field"
}

\author{
Jakfar Sodi' ${ }^{1)}$, Dyah Rini Ratnaningsih' ${ }^{2)}$, Dedy Kristanto ${ }^{2)}$ \\ ${ }^{1)}$ PT. Pertamina EP \\ 2) Petroleum Engineering Department UPN "Veteran” Yogyakarta \\ * email correspondence: jakfarjakpres@gmail.com
}

\begin{abstract}
"Jaso field" is located the South Sumatra basin, Indonesia. The lithology of this field is dominated by limestone / carbonate reservoirs with varying permeability (low / tight to high / porous). Acid Fracturing stimulation has been applied to develop this field, because in ideal conditions (with the solubility test between acid and formation $>80 \%$ ) wormholes will be made in the formation to increase reservoir conductivity and productivity. However, in the Jaso oil field, in some special cases, acid injection did not provide satisfactory results for increasing well conductivity and productivity.

In this thesis, we conduct research and evaluation of wells in Jaso field. For example: JS-28, JS-11 and JS-40 are oil wells in the Jaso field with low / narrow reservoir permeability and production rates. Stimulation has been carried out in the JS28 well, but the results are still below the acid expectation even though the intermediate solubility test (solubility test) is more than $88 \%$.

Hydraulic Fracturing with the sandfracturing method (injecting sand proppant with high pressure and exceeding the gradient fracture) has been successfully applied to three wells in the Jaso Field by increasing the oil production rate by more than 100 bopd per well. With this case study, we find that the application of hydraulic fracturing (sandfracturing) with thrusters is not limited to sandstone / sandstone reservoirs, but that this method can be successfully applied to increase the conductivity and productivity of carbonate reservoirs (in special cases) taking into account several parameters of integrity. reservoir wells and characteristics.
\end{abstract}

Keywords : acid fracturing, carbonate reservoir, hydraulic fracturing, low permeability, proppant

\section{INTRODUCTION}

Fracturing is performed by pumping the fracture fluid with pressure over the gradient fracture into the formation. The process of sand fracturing is producing a path of increased conductivity from the reservoir to the wellbore by creating a fracture, and then propping it permanently open. fluid pumped at high rate, high pressure into formation. Fractures are created on either side of the well once fracture is created; proppant is pumped.

The Jaso Field was discovered in November 1997, with an initial production rate of 1,085 BOPD, and very low water content. Reservoir Jaso is in the Formation $\mathbf{J}(\mathrm{JF})$ which is a carbonate rock at a peak depth of $-2,000$ mbpl. Reservoir initial pressure 3,205 psi reservoir temperature $280^{\circ} \mathrm{F}$ and bubble pressure 2,500 psi, the reservoir is undersaturated.

This paper discusses how to increase the conductivity of carbonate reservoirs other than by stimulating acidizing. With the application of hydraulic fracturing by injecting sand (proppant) into the carbonate reservoir formation, it can increase the conductivity around the wellbore and increase well production. In this paper, the analysis includes design fracturing, inflow performance well, economic analysis and the result of project.

\section{LITERATURE REVIEW}

\subsection{Hydraulic Fracturing Mechanism}

Hydraulic fracturing is a technique used to make conductive channels in small permeability formations, where this channel will be used as a way to produce oil and gas to the wellbore. Fractures begin to form when the velocity of the fluid being pumped is greater than the velocity of the fluid that is lost or enters the formation, where at this time the fractures can be formed because the high fluid pressure has been able to pass the fracture strength of the formation.

The proppant material will then be injected together with the fracturing fluid at a certain concentration so that the fractures that have been formed do not close again. The fracture fluid that is injected at this stage must have a certain viscosity so that it can carry the proppant into the fracture without settling and the proppant used must have sufficient strength to hold the fracture open. 
Hydraulic fracturing is typically carried out in low permeability formations, with the intention of forming new pores which aim to increase the permeability around the fractured formation by a distance along or as far as the formed fracture. Reservoir rocks are fractured by applying hydraulic pressure to exceed the strength of the forces that maintain the integrity of the formation rock.

In hydraulic fracturing operations, it is necessary to consider the following matters, namely: rock mechanics, fracturing fluid mechanisms and fracture geometry.

\subsubsection{Rock Mechanics}

Stress is defined as the derivative of the force per unit area of material subjected to this force. Stress is divided into three types, namely: maximum stress $\left(\sigma_{1}\right)$, intermediate stress $\left(\sigma_{2}\right)$ and minimum stress $\left(\sigma_{3}\right)$ where the magnitude and direction of the stress itself varies depending on the geological conditions. Figure 1. shows some of the major stress forms experienced by the formation at a certain depth.

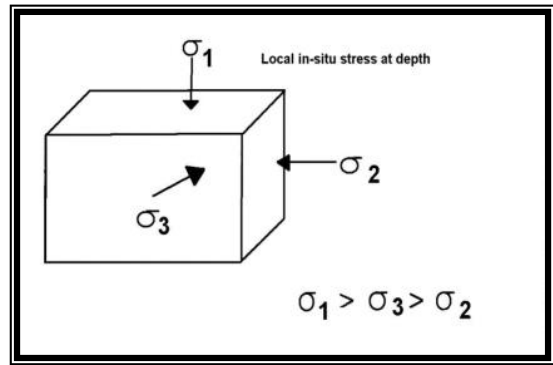

Figure 2.1.

In-situ Local Stress on Rocks (Bambang Tj, 2005)

Stress plays an important role in fracture formation because the magnitude and direction of stress determine the direction of the fracture, the shape of the fracture, and the amount of pressure needed to create and extend the fracture. The direction of the fracture will be perpendicular to the value of the smallest stress. For example, if the horizontal stress value $\left(\sigma_{3}\right)$ in the image above is minimum, the fracture will be vertical.

Other rock mechanical properties also need to be considered to design a hydraulic fracture in addition to rock stress. Poisson's Ratio is defined as the ratio between lateral expansion and longitudinal rock contraction under uniaxial stress conditions. Poisson's price ratio serves to change the effective vertical stress component into effective horizontal stress.

Another parameter that is not less important is Young's Modulus, defined as the ratio between stress and strain at uniaxial stress. Strain $(\varepsilon)$ is defined as the deformation or alteration of the relative position of points on the object subjected to stress.

The modulus value of a material represents the stiffness of the material, where the modulus value will be large for a chewy material, and vice versa. Rocks that are soft on hydraulic fracturing will produce narrower fractures compared to rocks that have a small modulus value.

\subsubsection{Fracturing Fluid Mechanisms}

The fracturing fluid in hydraulic fracturing is used to make fractures and bring proppants into the fracture, therefore the viscosity of the fracturing fluid needs to be controlled through its rheological properties to minimize the fluid loss factor.

\subsubsection{Fracture Direction}

Fractures will be produced vertically if the value of the smallest stress which is assumed to be the minimum horizontal stress has a value smaller than the absolute horizontal stress and vertical stress, on the contrary on a shallow surface (for example on an eroded surface) the direction of the fracture will be horizontal. The price of overburden stress in this situation will decrease, but the minimum and absolute horizontal stress remains the same.

\subsection{Fracture Conductivity}

The conductivity of the fracture is related to the permeability of the proppant and the width of the fracture filled with the proppant. The proppant has a permeability greater than $200 \mathrm{D}$ if there is no stress acting on the proppant. 


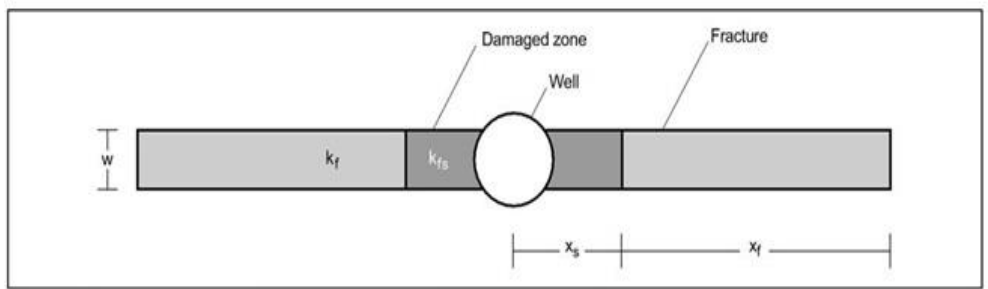

Figure 2.2.

Fracture Conductivity (Economides, Michael J,. 2000)

The conductivity of the fractures will decrease as the well ages. This is due to the increased stress suffered / experienced by fractures, where changes in the stress price will affect the strength of the proppant which will result in the entry of the proppant into the formation (proppant embedment) so that it will result in the rupture of the proppant and cause damage due to residual gel.

\subsection{Prediagnostic Treatment Test}

The purpose of this pretreatment diagnostic test is to determine the parameters that affect the fracture process, such as fracture closure pressure, fluid leak-off parameters, fracture extension or propagating pressure, resistance around the wellbore., height and length of fracture and reservoir permeability.

\subsubsection{Step Rate Test}

Includes injection of clean gel at several stable rates, starting with the rate at the matrix rate then increasing to a rate above the fracture extension pressure. The step rate test is generally performed to identify the pressure and rate of fracture extension (fracture extension pressure and pressure extension rate).

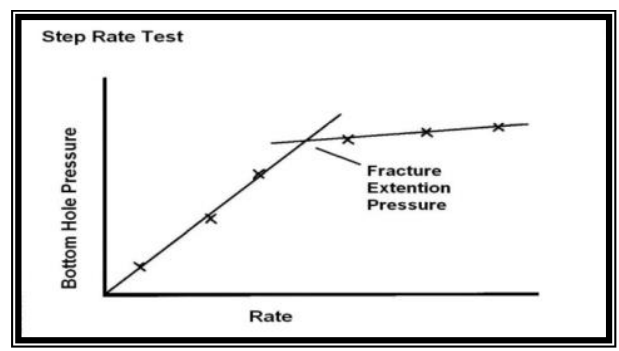

Figure 2.3.

BHP vs Injection Rate in the step rate test (Bambang $\mathrm{Tj}, 2005$ )

\subsubsection{Step Down Test}

The step-down test is mainly used to determine the presence of obstacles around the wellbore, either due to tortuosity or due to perforation friction. This test is usually done before the injection stage of the minifrac. Observing the variation in the graph of the bottom pressure versus the decrease in pumping rate, the resistance around the wellbore can also be detected as in Figure 6.8. the following:

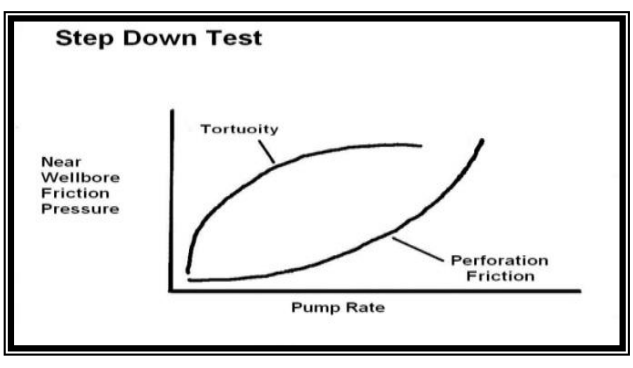

Figure 2.4.

Identification of Obstacles Around the Well Hole with a Step Down Test (Bambang Tj, 2005) 


\subsubsection{Minifracturing}

Includes several stages of tests carried out to determine the parameters required for hydraulic fracturing planning, namely:

- Flow back test, measures formation pressure when pumping is stopped (instantaneous shut-in pressure) and closure pressure.

- Shut-in test, measures the fluid loss characteristics of fracturing fluid, estimates fracture geometry and closure pressure.

\subsection{Fracture Geometry}

The fracture geometry can be expressed by means of a model or illustration, where the model also describes the relationship between the properties of rock and fracturing fluid as well as the pressure distribution in the porous media. There are two models commonly applied to fracture analysis, namely if the fracture length is greater than the fracture height (Xf >> Hf) then the model used is the PKN (Perkins, Kern \& Nordgen) model, and vice versa if the fracture length is shorter than the fracture height. (Xf $\ll<\mathrm{Hf}$ or Xf Hf) will be used the KGD model (Kristanovich, Gertsma \& de Klerk). Both models, both PKN and KGD, assume the fracture height is the same as the formation thickness.

\subsubsection{PKN Model}

The PKN model has an ellipse-shaped slice in front of the well with its maximum width located in the middle of the ellipse. Figure 3.10. The following illustrates the form of the PKN model.

The model is based on the assumption that:

1. The fracture length / fracture penetration is much greater than the fracture height (Xf $>>\mathrm{Hf}$ ).

2. The height of the fracture is equal to the thickness of the reservoir.

3. The pressure is considered constant in the direction of the vertical section; the rock stiffness reacts vertically.

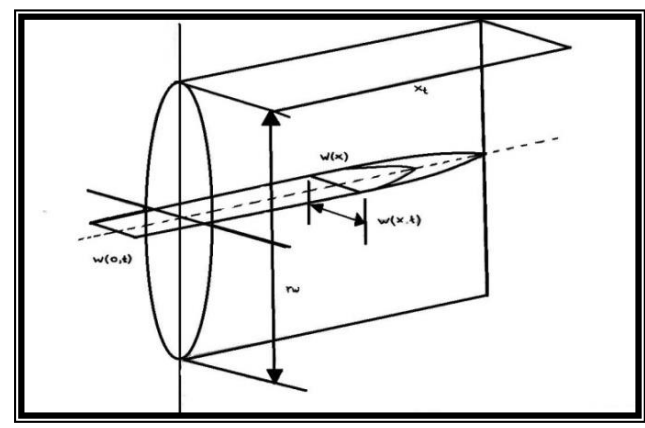

Figure 2.6.

PKN Schematic Model (Economides, Michael J., 2000)

Based on the above assumptions, this method is suitable to be applied to formations with low permeability. This model has an elliptical shape in the borehole, maximum width at the center of the ellipse, with zero width at the top and bottom.

\subsubsection{KGD Model}

KGD model - as seen in Figure 6.11. - is the result of a rotation of 90o from the PKN model and is generally more suitable for most of the formed fracture geometries. The KGD model is the same width (like a rectangle) along the fracture and is a half ellipse at the end. The fractional KGD model is relatively shorter, wider with greater conductivity than the PKN model.

The assumptions used in the KGD model are:

1. The fracture height is longer than the fracture length (hf $>\mathrm{xf}$ )

2. The height of the fracture is equal to the thickness of the reservoir.

3. Rock stiffness acts in a horizontal direction. 


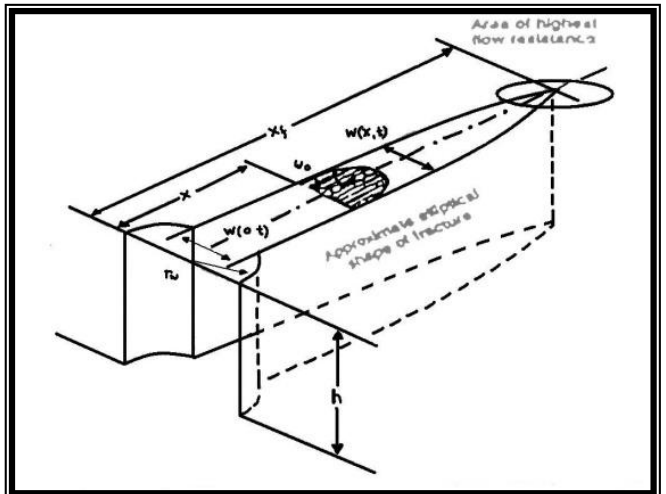

Figure 2.7.

KGD Schematic Model (Economides, Michael J,. 2000)

\subsubsection{Tree Dimensional}

It is a type of 3-dimensional fracture with vertical and horizontal propagation, with the length and width being the aspect ratio with the PKN model approach. When the limits of tension and strength are not included, the model is almost like vertical radial geometry, with this model the most realistic geometric model is obtained and can be used for all types of aspects. Length and width ratio. The figure below shows the 3-dimension profile of the fracture geometry, this model takes the geometric boundary as a parameter.

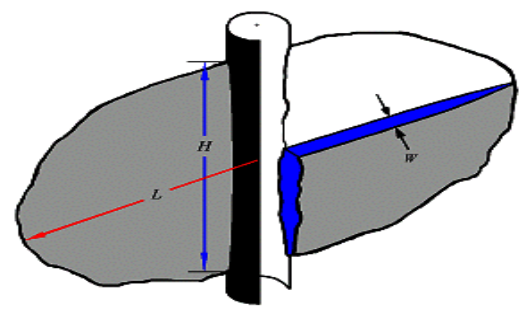

Figure 2.8

3-dimensional fracture geometry (Economides, Michael J,. 2000)

To use 3 dimensional models effectively. The formation must describe fluid loss and rock properties. To obtain better formation characteristics, the models allow the use of up to 1000 rock layers and reservoir properties.

\section{METHODOLOGY}

A schematic description of the methodology of this paper is in Figure 4. The methodology we used in this paper starts with data preparation, as shown in Figure 4. The data preparation includes Reservoir data (petrophysical data, reservoir PVT data, reservoir thickness, Well data (well depth, tubing length and diameter, choke size, Pwh, and well flow rate),Fract threat data (Fluid \& proppant Fracture. After that, Fracture dimension data analysis data is done to applicate in nodal analysis. Then, matching data performance well with data fracture and nodal analysis. Finally, the production performance \& economic analysis to get the conclusion that the project economically. 


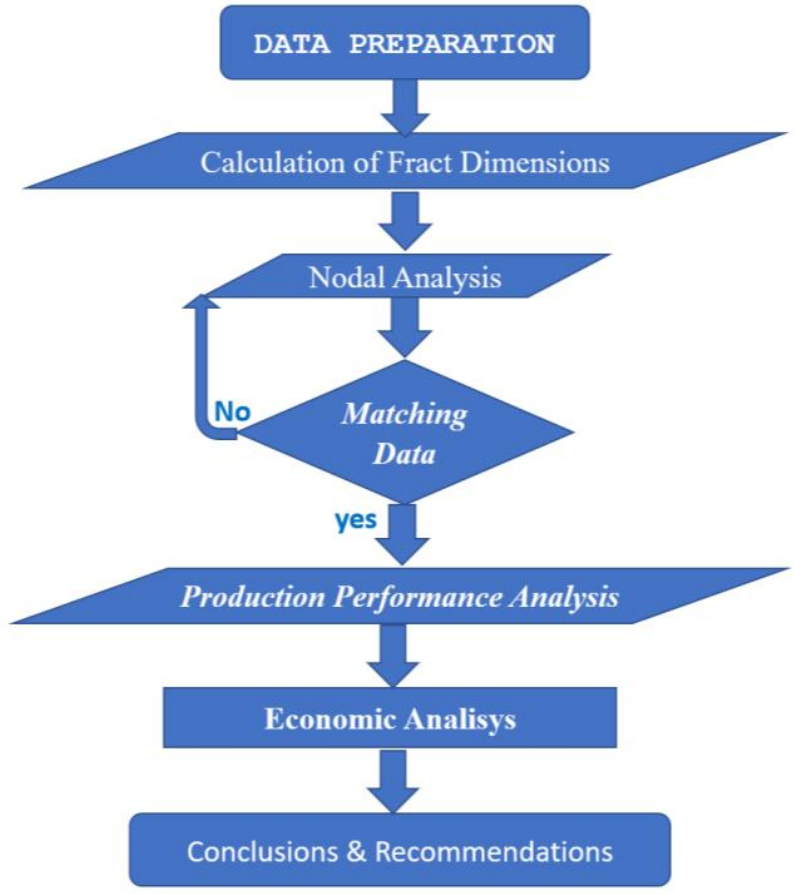

Figure 3.1. Methodology of Hydraulic Fracturing Analysis

\section{RESULTS AND DISCUSSION}

\subsection{Hydraulic Fracturing Analysis}

Based on the optimum work design results from a simulation study, then the execution is carried out in the field. In the implementation in the field there are several series of work processes before the main fracturing is carried out. This is done to obtain the required data so that the implementation of the main fracturing will run as expected. The following will discuss the implementation of hydraulic fracturing in the JS-11 well.
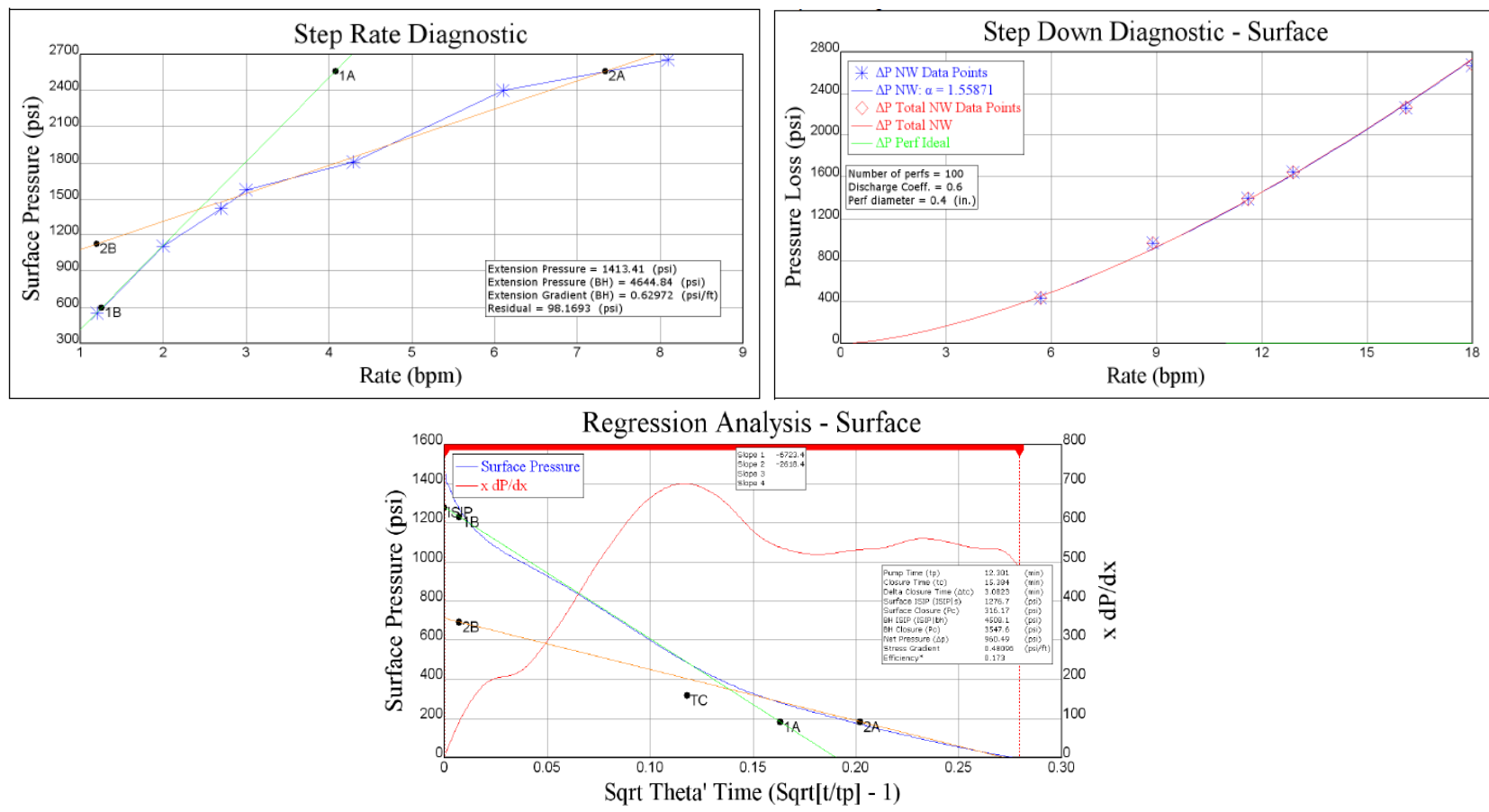

Figure 4.1. Steprate $\&$ Minifract analysis JS-11 


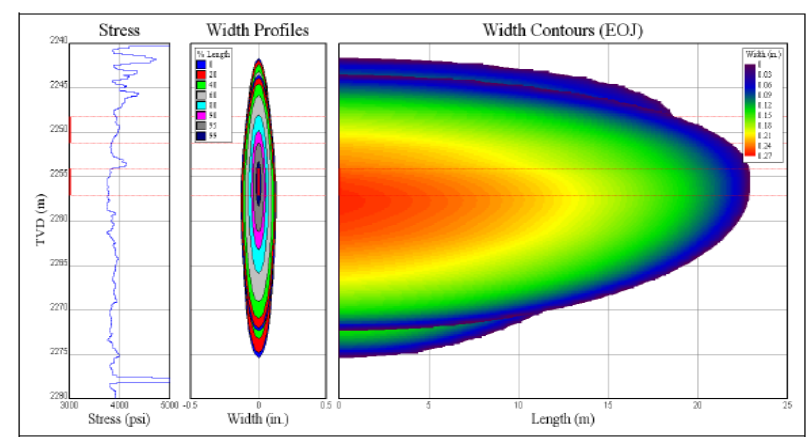

Figure 4.2. Geometry Profile of JS-11 Well Actual Fracture

The results of the step-up test with MFrac software, namely the step up diagnostic of the JS-11 well can be seen in Figure 4.1, From the intersection of the lines, the fracture extension pressure of the well will be obtained at 4644.84 Psi (@ bottomhole), 1413,341 Psi (@ surface) at a rate of 2.5 bpm (pressure extension rate) with a gradient extension of 0.629 Psi/ft. The results of the step-down test with MFrac software, namely the step down diagnostic of the JS-11 well and can be seen in Figure 4.1, From the step down diagnostic graph, the formation of a line that is concave upwards indicates a well bore friction effect.

\subsection{Result}

Hydraulic fracturing carried out on the JS-11 well in the J layer (limestone) aims to increase the well's ability to produce. Several reasons for stimulating hydraulic fracturing in the JS-11 and JS-28 \& JS-40 wells, namely:

1. To increase the production of these wells.

2. Overcoming damage problems seen from small well production (JS-11 and JS-28 with gross below 100 bfpd and JS40 no-influx due to drilling damage)

3. Not yet optimal acidizing stimulation in limestone wells with low permeability.

4. Large remaining reserves.

These things are the basic considerations for hydraulic fracturing. The implementation of hydraulic fracturing is expected to improve the damage zone and form a new conductive channel, so that hydrocarbons can flow more easily from the formation to the wellbore which will increase the amount of production from the well.

Based on the permeability figures, the JS-11, JS-28 and JS-40 wells have low permeability numbers. With this small permeability figure, the well deserves to be treated with hydraulic fracturing, because the purpose of stimulating hydraulic fracturing is to increase the permeability and conductivity of the well which is small or has no way for the fluid it contains. For this reason, hydraulic fracturing stimulation is necessary to bridge the skin formed in front of the perforation hole (skin by pass). And based on theory, hydraulic fracturing stimulation also aims to enlarge the radius of the wellbore. It can be seen from the Darcy flow equation that reducing the effect of skin and enlarging the radius of the well can increase the flow rate of the well. The Darcy flow equation is:

$$
\mathrm{q}=\frac{2 \pi k h(P i-P w f)}{\mu B o \ln \left(\frac{r e}{r w}\right)+S}
$$

Where $\mathrm{k}=$ formation permeability, $\mathrm{h}=$ formation effective thickness, $\mathrm{Pi}=$ formation pressure, Pwf = well bottom flow pressure, $\mu=$ viscosity, $\mathrm{Bo}=$ formation volume factor, $\mathrm{re}=$ drainage radius, $\mathrm{rw}=$ wellbore radius, and $\mathrm{S}=\mathrm{skin}$.

The geometric fracture results obtained after the main fracturing activity is complete have a value that is not much different from the prediction / design that has been made. Based on manual evaluation or fracture calculation using PKN $2 \mathrm{D}$, the fractures that are formed have differences compared to the actual ones. This is estimated because when evaluating the fracture geometry manually, the fracture height is considered constant, while in the planning / design and actual conditions the fracture height is not constant.

The number of pads and slurries used during the hydraulic fracturing process also has differences with the calculation results. This is due to the safety factor, where the safety factor number is determined with the aim of avoiding the lack of material for hydraulic fracturing in the field, which in the event of a well can die and cause big losses. However, the number of proppants and the working time during the hydraulic fracturing process have the same value. Judging from the production results obtained after the hydraulic fracturing process is carried out, this stimulation process can be said to be successful because well production has increased significantly from its initial production. 


\begin{tabular}{|c|c|c|c|}
\hline Well Name & JS-11 & JS-28 & JS-40 \\
\hline \multicolumn{4}{|l|}{ Reservoir Properties } \\
\hline Formation & J & J & J \\
\hline Completion type & \multicolumn{3}{|c|}{ Single (Cased Hole) } \\
\hline Porosity (\%) & 15 & 12.4 & 13 \\
\hline Permeability (mD) & 18.4 & 1.46 & 5.4 \\
\hline Net pay zone $(\mathrm{m})$ & 26 & 18 & 15 \\
\hline Pressure reservoir (Psi) & 1700 & 1700 & 1700 \\
\hline Temperature reservoir ( F) & 270 & 270 & 270 \\
\hline Drive Mechanism & Waterdrive & Waterdrive & Waterdrive \\
\hline $\operatorname{Re}(\mathrm{m})$ & 250 & 250 & 250 \\
\hline \multicolumn{4}{|l|}{ Threatment Fracturing } \\
\hline Half Length $(\mathbf{X} \mathbf{f}, \mathbf{m})$ & 22.94 & 23.549 & 69.07 \\
\hline Fract Height $(\mathrm{Hf}, \mathrm{m})$ & 22.87 & 7.381 & 21.51 \\
\hline Witch average (Wf, inchi) & 0.31 & 0.41 & 0.15 \\
\hline Fract Conductivity (WKf, mD-ft) & 4014.7 & 950.65 & 2451 \\
\hline Fracture conductivity dimensionless (FCD) & 2.67 & 1.23 & 2.18 \\
\hline Sand in formation, lbs & 15.164 & 7.586 & 45.209 \\
\hline \multicolumn{4}{|l|}{ After Fracturing } \\
\hline Production test before fract (bfpd/bopd/wc) & $188 / 4 / 98 \%$ & $132 / 13 / 90 \%$ & 0 \\
\hline Production test after fract (bfpd/bopd/wc) & $596 / 131 / 77 \%$ & $592 / 185 / 67 \%$ & $440 / 359 / 21 \%$ \\
\hline Gain Production initial (Qoi, bopd) & 127 & 172 & 359 \\
\hline
\end{tabular}

Table 4.1. Result \& Data Hydraulic Fracturing
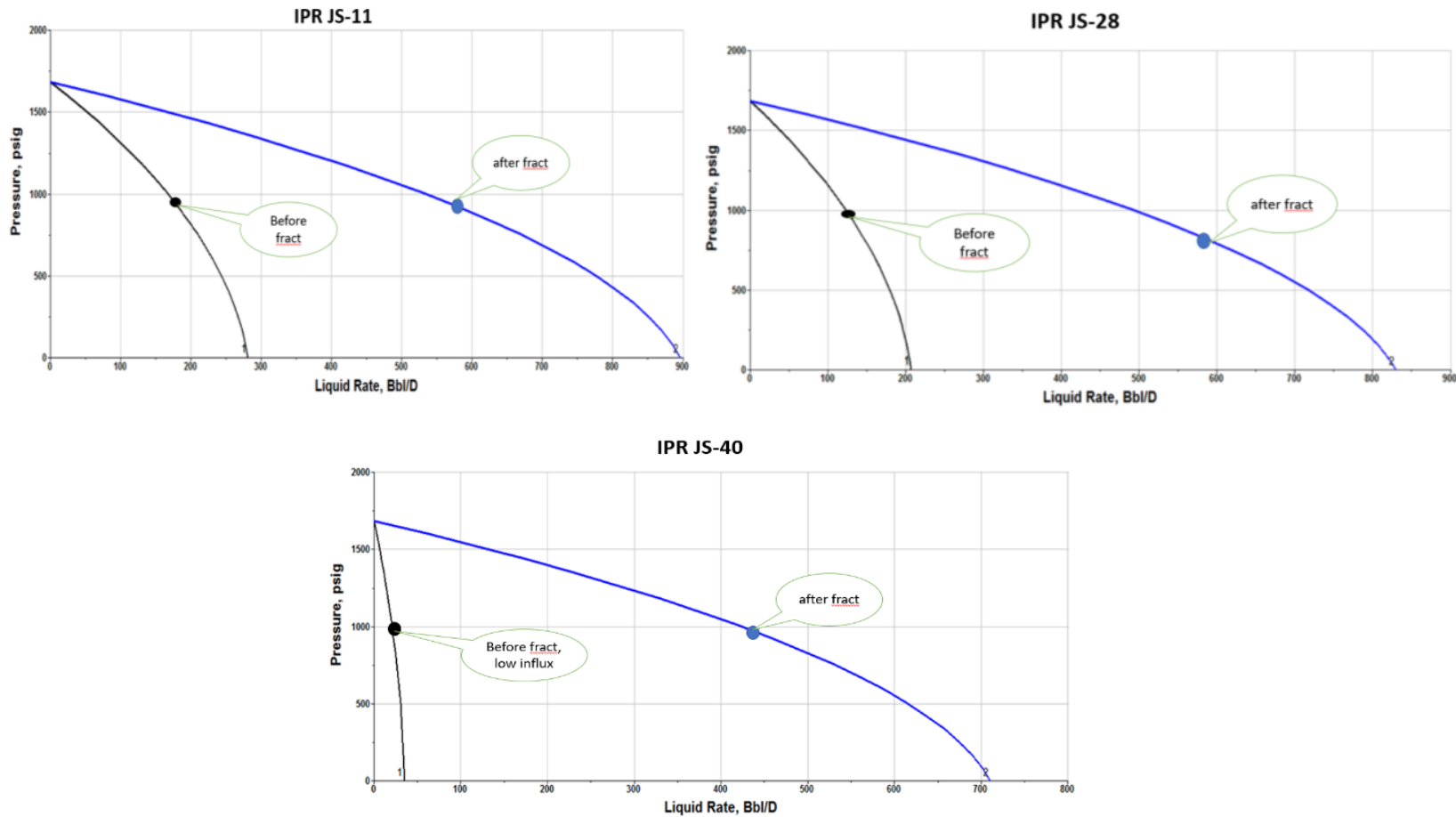

Figure 4.3. Comparation est. IPR before and after hydraulic Fracturing job.

\section{CONCLUDING REMARKS}

From the results of hydraulic fracturing in the JS-11, JS-28 \& JS-40 wells in the JS field, the following conclusions and recommendations can be drawn:

1. Hydraulic fracturing by injecting sand (proppant) into the formation, can be an alternative to increase the conductivity of wells in the carbonate reservoir apart from the acidizing stimulation method.

2. Some conditions that must be met in hydraulic fracturing applications in carbonate reservoirs are low solubility $(<60 \%)$, tight formation $(<<50 \mathrm{mD})$ must also be far from the water zone $(>100 \mathrm{ft})$ and high oil reserves $(>60 \mathrm{MSTB}$ / well) and the reservoir pressure is still high (Pressure gradient $>0.2 \mathrm{Psi} / \mathrm{ft}$ ). 
3. Implementation of Hydraulic fracturing JS-11 well with fracture length (xf) $22.94 \mathrm{~m}$, fracture width (wf) 0.31-inch, fracture height (hf) $22.87 \mathrm{~m}$, and sand in formation $15.164 \mathrm{lbs}$, resulting in Fracture conductivity dimensionless (FCD) 2.67 and an increase in Qmax from $280 \mathrm{bfpd}$ to $900 \mathrm{bfpd}$, an increase in Qoi production with a gain of $127 \mathrm{bopd}$

4. Implementation of Hydraulic fracturing JS-28 well with fracture length (xf) $23.54 \mathrm{~m}$, fracture width (wf) 0.41 -inch, fracture height (hf) $7.381 \mathrm{~m}$, and sand in formation $7.586 \mathrm{lbs}$, resulting in FCD 1.23 and an increase Qmax from 205 bfpd to $830 \mathrm{bfpd}$, the increase in Qoi production with a gain of $172 \mathrm{bopd}$.

5. Implementation of Hydraulic fracturing JS-40 well with fracture length (xf) $69.07 \mathrm{~m}$, fracture width (wf) 0.15 inch, fracture height (hf) $21.51 \mathrm{~m}$, and sand in formation 45.209 lbs, resulting in FCD 2, 18 and an increase in Qmax from $40 \mathrm{bfpd}$ to $705 \mathrm{bfpd}$, an increase in Qoi production with a gain of $359 \mathrm{bopd}$.

6. From the hydraulic fracturing stimulation project, NPV 2074,000 USD, IRR 223.7\%, POT 0.31 month and PI 3.24 US \$ / US \$ were obtained, which are very economical projects.

\section{REFERENCES}

Beggs, H. Dale. 1991. Production Optimization Using Nodal Analysis. OGCI and Petroskills Publication, Tulsa, Oklahoma,

Bambang Tjondrodipoetro,M.Sc. 2005. Acidizing and Hydraulic Fracturing, Intermediate Course, Yogjakarta.

BJ. 2001. Manual Fract.

Dedy Kristanto, Doddy A, Dadang R, Dedi CA, V. 2020. Pengurasan Minyak Tahap Lanjut, Yogjakarta.

Dedy Kristanto, Dadang R, Asep KP, V.Dedi CA. 2020. Peningkatan Produksi Lapangan Minyak Tua (Teori dan Aplikasi). Yogjakarta.

Economides, Michael J. 2000. Reservoir Stimulation, Schlumberger, Texas.

PEP. 2020. Well maintenance work data \& Postjob Report Fracturing.

Santoso, Anas Puji. 1988. Teknik Produksi I, UPN “Veteran”, Yogyakarta.

Schlumberger. 1985. “PIPESIM Suite User Guide,” USA. 